\title{
Análise das experiências em iniciações científicas de estudantes de medicina do Campus São Paulo/UNIFESP
}

\author{
Analysis of the experiences with scientific initiations of medical students from the \\ Campus São Paulo/UNIFESP
}

\author{
Lucas Henrique Pereira, Mariana Cabral Schveitzer,
}

Pereira LH, Schveitzer MC. Análise das experiências em iniciações científicas de estudantes de medicina do Campus São Paulo/ UNIFESP / Analysis of the experiences with scientific initiations of medical students from the Campus São Paulo/UNIFESP. Rev Med (São Paulo). 2020 jul.-ago.;99(4):326-34.

RESUMO: Iniciações científicas são o primeiro contato dos estudantes de medicina com a pesquisa e são centrais no desenvolvimento do pensamento crítico e de habilidades pessoais, apesar de dificuldades como falta de tempo e de orientação apropriada. Os objetivos foram analisar as experiências que estudantes de medicina da Universidade Federal de São Paulo (Unifesp) tiveram com seus projetos de iniciação científica e identificar aspectos positivos e negativos desse programa nesta universidade. Estudantes de medicina da Unifesp de todos os anos foram convidados a escrever anonimamente, utilizando a plataforma online RedCap, um relato sobre suas experiências com projetos de iniciação científica. Os textos foram lidos e divididos em categorias relativas a experiência geral e em subcategorias relativas aos benefícios, dificuldades e motivações presentes nos relatos. Foram analisadas 71 respostas, sendo que 60 relataram uma boa experiência em seus projetos e 11, uma experiência ruim. Os principais benefícios citados foram contato com o método científico e desenvolvimento pessoal. As principais dificuldades foram um relacionamento conflituoso com o orientador e a falta de tempo. As principais motivações foram o contato com uma área de interesse e o enriquecimento curricular. Desenvolver um projeto permite praticar o método científico, estimula o pensamento crítico e a melhoria de habilidades pessoais, como trabalho em equipe e gerenciamento de tempo. Um bom relacionamento com o orientador é importante, uma vez que os estudantes, devido à falta de experiência, não têm a capacidade de conduzir as pesquisas sozinhos. Conciliar os projetos com a graduação é uma dificuldade, gerando a discussão de como as faculdades de medicina poderiam incorporar a iniciação científica no currículo oficial. A motivação pelo enriquecimento curricular mostra preocupação com o processo de seleção para a residência médica, podendo criar um sentimento de obrigatoriedade de engajamento em pesquisa, gerando decepção com o meio acadêmico e resultados pouco significativos.

Descritores: Pesquisa; Ciência; Narração; Estudantes de medicina.
ABSTRACT: Scientific initiations are the first opportunity that medical students have to experience research and are central in the development of critical thinking and decision-making skills, regardless of some difficulties like lack of time and adequate orientation. The objectives were to analyze the experiences that medical students from the Universidade Federal de São Paulo (Unifesp) had with their scientific initiation projects and to identify good and bad aspects of this program in our university. Medical students from all grades of Unifesp were asked to write anonymously, using an online platform (RedCap), a report about their experiences with their scientific initiation projects. The texts were read and divided into categories regarding general experience and into subcategories regarding motivations, benefits, and difficulties cited by the students. We received 71 responses, 60 reporting good experiences with research and 11 reporting bad experiences. The main benefits cited were contact with the scientific method and personal development. The main difficulties were a conflicted relationship with the supervisor researcher and lack of time. The main motivations were the contact with an area of interest and curriculum enrichment. The majority of students reported a good experience with their projects. The scientific project allows the students to practice the scientific method, critical thinking and to improve personal skills, like teamwork and time management. A good relationship with the supervisor is important, once the students, due to lack of experience, don't have the capability to conduct research by themselves. To conciliate research with the medical undergraduate is challenging, creating a discussion of how the medical schools could incorporate research into their official curriculum. The curriculum enrichment motivation denotes worry about the residency selection process, which can create a feeling of obligation for the engagement in research, leading to disappointment with the academic world and non-significant outcomes.

Keywords: Research; Science; Narration; Students, medicine.

Apresentado no II Congresso Internacional em Ciências da Saúde, 2019, Unimontes, Montes Claros e no VI Congresso Acadêmico da Unifesp - Ciência e Universidade: Transformações para a Sociedade, 2020, São Paulo, SP.

1. Acadêmico de medicina da Universidade Federal de São Paulo, UNIFESP. https://orcid.org/0000-0001-5507-2843. Email: 1hpereira30@gmail.com.

2. Professora Adjunta do Departamento de Medicina Preventiva da Escola Paulista de Medicina da Universidade Federal de São Paulo/UNIFESP. https:// orcid.org/0000-0001-9833-2932. Email: mariana.cabral@unifesp.br.

Endereço para correspondência: Lucas Henrique Pereira. Rua Botucatu, 740 - Vila Clementino, São Paulo, SP. CEP:04023-900. 


\section{INTRODUÇÃO}

A iniciação científica é definida como uma de pesquisa científica realizada por graduandos de cursos superiores, sob a orientação de um docente, possibilitando conhecimento do método científico e a integração com a área acadêmica, havendo ou não fomento financeiro.

Vivências de alunos de graduação com pesquisas em universidades brasileiras datam da década de 40 , porém a institucionalização dessa prática ocorreu em 1951 com a criação do Conselho Nacional de Desenvolvimento Científico e Tecnológico (CNPq), que passou a financiar os projetos de iniciação científica, prática que, atualmente, também é realizada pelas Fundações de Amparo à Pesquisa (como a FAPESP, por exemplo) e por outras vias de fomento. A prática se expandiu a partir da criação do Programa Institucional de Bolsas de Iniciação Científica (PIBIC) em 1988 pelo CNPq, a partir do qual as bolsas passaram a serem cedidas diretamente as universidades e institutos de pesquisa, estando este programa, pelas últimas análises, bastante difundido nas universidades brasileiras ${ }^{1,2}$.

Desde sua criação, a iniciação científica vem se consolidando como um instrumento de integração entre o ensino e a pesquisa, dois pontos constituintes do ensino superior brasileiro. Diversas vantagens decorrentes da participação nesse tipo de projeto podem ser citadas: aproximação do aluno de graduação com o meio científico e com uma área de seu interesse, desenvolvimento da capacidade de análise crítica da produção científica, facilitação do desenvolvimento de projetos de pósgraduação, desenvolvimento de habilidades pessoais como independência e pró atividade ${ }^{2,3}$. Porém, uma série de dificuldades também pode existir ao longo do projeto: falta de conhecimento e/ou do tempo necessários para o desenvolvimento do projeto, problemas com o orientador e/ ou com o tema, oferta limitada de bolsas de financiamento, falta de orientação por parte da instituição de ensino e problemas de infraestrutura ${ }^{2}$.

Tratando especificamente dos cursos de medicina, encontra-se nas "Diretrizes Nacionais Curriculares dos Cursos de Medicina" a necessidade do desenvolvimento de atividades além das disciplinas obrigatórias na graduação, sendo um exemplo disso a realização de iniciações científicas ${ }^{4}$. A medicina oferece amplo contato com áreas de pesquisa que recebem grande investimento e que podem gerar impactos sociais importantes. Além disso, algumas das habilidades já citadas que são estimuladas em iniciações científicas, como a diferenciação de informações cientificamente válidas daquelas sem consistência, são essenciais para o futuro médico ${ }^{1}$. Não há, no entanto, projetos estruturados e institucionalizados de atração dos alunos de medicina para a área de pesquisa no Brasil, como acontece em alguns outros países, como a Noruega ${ }^{5}$. Isso, aliado ao fato do curso médico ser caracterizado por uma grande carga horária e alta exigência com seus discentes, pode dificultar o engajamento nesses projetos durante a graduação.

As pesquisas sobre o tema, apesar de escassas, indicam uma grande participação dos estudantes de medicina em projetos de pesquisa durante a graduação, motivados por enriquecimento curricular, recebimento de bolsas e aproximação de áreas de interesse. Porém, endossando o que foi discutido acima, as principais dificuldades encontradas são a falta de tempo para o envolvimento com esse tipo de atividade e, ainda, a falta de estrutura e incentivo institucional existente em algumas universidades ${ }^{6,7}$.

Os objetivos deste trabalho são analisar a experiência dos estudantes de medicina da Universidade Federal de São Paulo (UNIFESP) que se envolveram em projetos de iniciação científica, além de entender as motivações para tal envolvimento, as dificuldades encontradas e a percepção individual do resultado desses projetos, além da opinião dos participantes sobre outras questões relativas à iniciação científica na graduação, tentando estabelecer seus pontos positivos e negativos.

\section{MÉTODO}

Este estudo é descritivo e qualitativo ${ }^{8}$. Os participantes foram alunos de medicina do primeiro ao sexto ano da Unifesp que estavam ou já haviam estado envolvidos em projetos de iniciação científica. Os alunos foram selecionados a partir da técnica "bola de neve", com um aluno de cada ano sendo escolhido no início do projeto e, a partir desses, outros foram captados por indicação.

Um formulário online foi criado na plataforma REDcap e utilizado como instrumento de coleta de dados. Esse formulário garantia o anonimato do participante e apresentava o termo de consentimento livre e esclarecido do projeto, uma pergunta sobre o ano de graduação do participante, além da seguinte orientação: "A iniciação científica é uma das atividades extracurriculares nas quais os alunos de medicina se envolvem, sendo uma experiência muito particular para cada participante. Descreva como foi/é sua experiência com sua (s) iniciação (ões) científica (s), incluindo possíveis situações de desistência do projeto". Antes de ser enviado para os participantes da pesquisa, o instrumento de coleta foi testado com alunos de cursos de medicina de outras universidades e com residentes, para garantir a clareza das instruções e o funcionamento do sistema. Os participantes, após aceitarem participar da pesquisa, recebiam o link do formulário por e-mail, para que pudessem escrever seus relatos motivados pela frase supracitada. $\mathrm{O}$ envio dos formulários ocorreu de outubro de 2018 até janeiro de 2019. 
Os relatos tiveram possíveis trechos que pudessem revelar a identidade do autor retirados e, após uma primeira análise, foram separados em categorias quanto ao resultado final da experiência relatada. Dentro dessas categorias, foram criadas subcategorias que descrevem os benefícios, dificuldades e motivações citados pelos participantes. Toda essa análise foi feita por uma única pessoa.

\section{RESULTADOS}

\section{I) Ano dos participantes}

Foram obtidos 75 relatos, sendo que destes 4 foram excluídos devido a inadequação com a proposta por relatarem aspectos técnicos (assunto, metodologia, resultados) dos projetos e não as experiências propriamente ditas. A distribuição dos 71 relatos quanto ao ano da graduação em que seus autores estavam pode ser vista na Tabela 1.

Tabela 1: número de alunos participantes de acordo com o ano da graduação

\begin{tabular}{cccccccc}
\hline Ano & $\mathbf{1}^{\mathbf{0}}$ & $\mathbf{2}^{\mathbf{0}}$ & $\mathbf{3}^{\mathbf{0}}$ & $\mathbf{4}^{\mathbf{0}}$ & $\mathbf{5}^{\mathbf{0}}$ & $\mathbf{6}^{\mathbf{0}}$ & Total \\
\hline Número de alunos & 3 & 9 & 13 & 21 & 14 & 11 & 71 \\
\hline
\end{tabular}

\section{II) Categorias}

Os textos foram subdivididos em duas grandes categorias quanto ao resultado final da experiência relatada pelos alunos. As categorias são:

Categoria 1: iniciação científica como um aspecto positivo. Aluno expressa abertamente que a experiência foi positiva ou, no relato, apreende-se essa informação.

Categoria 2: iniciação científica como uma experiência negativa. Aluno expressa abertamente que a experiência foi negativa ou, no relato, apreende-se essa informação.

As categorias 1 e 2 receberam relatos de alunos que cursavam todos os anos da graduação, distribuídos de maneira homogênea.

$\mathrm{O}$ número de relatos alocados em cada uma das categorias pode ser visto na Tabela 2 .

Tabela 2: número de relatos alocados em cada categoria

\begin{tabular}{lccc}
\hline Categoria & $\mathbf{1}$ & $\mathbf{2}$ & Total \\
\hline Número de relatos & 60 & 11 & 71 \\
\hline
\end{tabular}

III) Benefícios e pontos positivos

Foram criadas subcategorias que agrupavam os diferentes benefícios e pontos positivos descritos pelos alunos em seus relatos com relação a experiência de fazer uma iniciação científica. As subcategorias e suas descrições podem ser vistas abaixo.

1) Contato e aprendizado da metodologia científica: conhecimento da elaboração, escrita, execução e interpretação de um projeto científico.

2) Desenvolvimento pessoal: desenvolvimento de características como organização, disciplina, autodidatismo, proatividade, trabalho em equipe multidisciplinar.

3) Proximidade/apoio/boa relação com orientador e/ou outras pessoas envolvidas na pesquisa: participação ativa e próxima do orientador/equipe no projeto é relatada como um ponto positivo.

4) Contato com área de interesse: contato com área de interesse e obtenção de mais conhecimento sobre ela.

5) Contato com o meio acadêmico e com um ambiente de pesquisa: conhecimento sobre o funcionamento do meio acadêmico, tanto de questões burocráticas (metodologias, funcionamento de um laboratório) quanto práticas (apresentação em congressos).

6) Motivação para escolha de futura carreira acadêmica: projeto como fator motivador para interesse profissional na área de pesquisa.

7) Presença de auxílio financeiro: recebimento de bolsa de uma agência de fomento.

8) Melhoria do currículo: publicação de artigos, apresentação em congressos, participação de eventos científicos.

9) Estímulo à graduação: participação no projeto estimulava o aluno a se dedicar mais a sua graduação.

10) Melhoria da relação médico paciente: aprimoramento das habilidades de relacionamento com pacientes.

11) Aplicabilidade do projeto: possível uso prático do resultado do projeto.

A frequência de citações de cada subcategoria nos relatos, bem como uma fase exemplificando cada uma delas podem ser vistas na Tabela 3 . 
Tabela 3: Frequência de citações de cada subcategoria de benefícios/pontos positivos e citação retirada dos relatos referentes àquela subcategoria

\begin{tabular}{|c|c|c|}
\hline Subcategoria & Frequência de citações & Trecho exemplo da subcategoria \\
\hline 1 & 23 & $\begin{array}{l}\text { "A minha iniciação científica vem me oferecendo algo que a graduação, em si, não } \\
\text { me disponibiliza e que acho essencial para a minha formação acadêmica, científica e } \\
\text { humana: o método científico". }\end{array}$ \\
\hline 2 & 13 & $\begin{array}{l}\text { "Também consegui desenvolver aspectos inerentes ao bom profissional dos dias de hoje, } \\
\text { como capacidade de liderança, espírito de equipe, comprometimento e proatividade". }\end{array}$ \\
\hline 3 & 13 & $\begin{array}{l}\text { "Para mim a experiência da iniciação está sendo muito boa, mas acredito que isso só } \\
\text { seja verdade porque minha orientadora é muito dedicada e comprometida com minha } \\
\text { pesquisa". }\end{array}$ \\
\hline 4 & 11 & $\begin{array}{l}\text { "É uma possibilidade para que o aluno consiga a autonomia para estudar um tema que } \\
\text { lhe desperte o interesse e proporcionar grande realização pessoal e profissional". }\end{array}$ \\
\hline 5 & 11 & $\begin{array}{l}\text { "A possibilidade de aprender como funciona a pesquisa clínica foi muito enriquecedora, } \\
\text { além de ter a oportunidade de apresentar o meu trabalho no congresso (...), uma } \\
\text { experiência marcante" }\end{array}$ \\
\hline 6 & 6 & $\begin{array}{l}\text { "Pretendo manter o meu vínculo com estudos científicos mesmo após a graduação, pois } \\
\text { a pesquisa me permitiu enxergar o além do que estava escrito nos livros e desenvolver } \\
\text { raciocínios clínicos diferenciados". }\end{array}$ \\
\hline 7 & 5 & $\begin{array}{l}\text { "Além disso, a remuneração da bolsa PIBIC tem sido importante para custear despesas } \\
\text { pessoais". }\end{array}$ \\
\hline 8 & 3 & $\begin{array}{l}\text { "O trabalho resultante de minha IC me levou a ganhar certificados e a realizar } \\
\text { apresentações em inglês, experiências inestimáveis que me garantiram preciosas } \\
\text { lembranças durante a graduação de medicina". }\end{array}$ \\
\hline 9 & 2 & $\begin{array}{l}\text { "Em comparação com a graduação, sinto que o projeto de iniciação foi a atividade que } \\
\text { mais me estimulou a buscar um conhecimento amplo e profundo, sem que houvesse } \\
\text { necessariamente uma obrigação para isso". }\end{array}$ \\
\hline 10 & 2 & $\begin{array}{l}\text { "(...) considerando que me ajudou bastante no desenvolvimento de relação médico- } \\
\text { paciente - fui me aperfeiçoando em como me comunicar com os pais e pacientes, como } \\
\text { convidá-los a participar da pesquisa, como explicar o preenchimento questionário } \\
\text { (bastante longo) de uma maneira simples, como lidar diante dos "nãos" e de reclamações } \\
\text { dos pais sobre a dinâmica do ambulatório". }\end{array}$ \\
\hline 11 & 1 & $\begin{array}{l}\text { "Por mais que dê trabalho eu considero que estou fazendo algo útil e isso faz toda a } \\
\text { diferença na hora de levar uma IC". }\end{array}$ \\
\hline
\end{tabular}

\section{III) Dificuldades e pontos negativos}

Foram criadas subcategorias que agrupavam as diferentes dificuldades e pontos negativos descritos pelos alunos em seus relatos com relação a experiência de fazer uma iniciação científica. As subcategorias e suas descrições podem ser vistas abaixo.

1) Falta de proximidade/participação/compreensão do orientador e/ou de outros membros da pesquisa: falta de apoio do orientador/equipe nas diferentes etapas do projeto ou uma relação conflituosa.

2) Incompatibilidade de horários/falta de tempo disponível: falta de tempo devido às atividades da graduação ou incompatibilidade de horários com os do local de execução do projeto.

3) Entraves burocráticos e falta de recursos: necessidade de cumprimento de burocracias (aprovação em comitês, execução de procedimentos, aprovação de bolsas) bem como a falta de materiais necessários para a execução do projeto.

4) Falta de conhecimento da metodologia de elaboração/desenvolvimento de um projeto: desconhecimento da metodologia de elaboração e seguimento de um projeto científico, desde sua escrita até sua execução e publicação.

5) Falta de orientação da universidade: falta de orientação por parte da universidade sobre quando realizar um projeto ou sobre os projetos disponíveis.

6) Dependência de terceiros para a realização do projeto: dependência de outras pessoas (pós-graduandos, técnicos, professores) para a realização do projeto.

7) Desinteresse/falta de proatividade do aluno: aluno faz autocrítica de que a falta de dedicação dele ao projeto 
foi um empecilho para o andamento deste.

8) Ausência de pensamento crítico no projeto: desenvolvimento de um trabalho mecânico, sem uso de raciocínio.

9) Dificuldade devido a língua inglesa: a falta de domínio da língua inglesa foi um empecilho para a leitura/ elaboração de artigos.

10) Falta de auxílio financeiro: falta de apoio de uma organização de fomento.

11) Estresse gerado pela pesquisa com animais: trabalho com animais gerando estresse e desgaste.

12) Falta de aplicabilidade da pesquisa: desmotivação por falta de aplicabilidade do projeto e de seus resultados.

A frequência de citações encontradas para cada uma das subcategorias, bem como uma fase exemplificando cada uma delas podem ser vistas na Tabela 4.

Tabela 4: Frequência de citações de cada subcategoria de pontos negativos e citação retirada dos relatos referentes àquela subcategoria

\begin{tabular}{|c|c|c|}
\hline Subcategoria & Frequência de citações & Trecho exemplo da subcategoria \\
\hline 1 & 12 & $\begin{array}{l}\text { "(...) minha orientadora é um pouco impaciente e demonstra não gostar de explicar } \\
\text { mais de uma vez a mesma coisa, então ela acaba ficando um pouco brava quando } \\
\text { perguntamos algo que não entendemos. Isso tem me feito bem mal, pois acabo deixando } \\
\text { comigo minhas dúvidas. Algumas vezes ela chegou até a nos destratar por não conseguir } \\
\text { fazer algum procedimento técnico que ela explicou apenas uma vez”. }\end{array}$ \\
\hline 2 & 8 & $\begin{array}{l}\text { "Assim, desisti do projeto por não haver flexibilidade de horário para eles me } \\
\text { acompanharem nos experimentos e por esses procedimentos levarem muito tempo, não } \\
\text { podendo ser realizados no horário do almoço (meu tempo disponível)". }\end{array}$ \\
\hline 3 & 8 & $\begin{array}{l}\text { "Um problema que estamos enfrentando no momento é a falta de recursos/materiais } \\
\text { para o projeto e, por isso, estamos parados por um tempo, fato que me aflige, pois há } \\
\text { prazo de término do projeto". }\end{array}$ \\
\hline 4 & 4 & $\begin{array}{l}\text { "Nessa minha primeira experiência, tive bastante dificuldades, principalmente por não } \\
\text { saber como funcionava muito bem essa "coisa" de iniciação científica - até onde eu } \\
\text { poderia chegar com aquela oportunidade". }\end{array}$ \\
\hline 5 & 2 & $\begin{array}{l}\text { "Iniciar um projeto científico numa Universidade tão reconhecida pela pesquisa foi um } \\
\text { tanto frustrante. É difícil saber o momento em que se deve começar essa trajetória e a } \\
\text { faculdade não lhe dá respaldo suficiente". }\end{array}$ \\
\hline 6 & 2 & $\begin{array}{l}\text { "(...) eu dependia da boa vontade de minha orientadora (...) e da boa vontade de } \\
\text { terceiros, como patologistas, pessoas que trabalham com corte de lâminas, etc.". }\end{array}$ \\
\hline 7 & 2 & $\begin{array}{l}\text { "Minha iniciação não foi tão proveitosa quanto eu esperava, como resultado da } \\
\text { combinação da minha falta de pró-atividade e da escassa experiência de meu professor } \\
\text { com alunos de IC". }\end{array}$ \\
\hline 8 & 2 & $\begin{array}{l}\text { "Estou completamente desestimulado a continuar, porque a minha função é basicamente } \\
\text { marcar exames. Não há aprendizado científico nisso". }\end{array}$ \\
\hline 9 & 2 & $\begin{array}{l}\text { "Porém, mesmo assim senti dificuldades por ter que conciliar provas da graduação com } \\
\text { a escrita do projeto, isso se agrava para mim pelo fato dos artigos de referência terem } \\
\text { sido todos em inglês, o que tornava a leitura um pouco mais devagar". }\end{array}$ \\
\hline 10 & 1 & $\begin{array}{l}\text { "Como ponto negativo, posso citar somente a não renovação da bolsa de iniciação } \\
\text { científica que, além de desestimulante para a continuidade do trabalho, faz perguntar } \\
\text { quais os horizontes da pesquisa científica no Brasil". }\end{array}$ \\
\hline 11 & 1 & $\begin{array}{l}\text { "(...) tudo isso não só era cansativo mas também psicologicamente desgastante, sendo } \\
\text { que eu chorava em vários momentos por ver os ratos sofrendo pelos estressores". }\end{array}$ \\
\hline 12 & 1 & $\begin{array}{l}\text { "Um dos maiores agravantes é que, no final, eu não sabia explicar exatamente por } \\
\text { que minha pesquisa tinha relevância, na verdade, até hoje eu não sei se realmente foi } \\
\text { relevante". }\end{array}$ \\
\hline
\end{tabular}

IV) Motivações

Foram criadas subcategorias que agrupavam as diferentes motivações para o envolvimento em iniciações científicas citadas pelos alunos em seus relatos. As subcategorias podem ser vistas abaixo.

1) Possibilidade de pesquisar sobre um assunto de interesse pessoal.
2) Enriquecimento do currículo.
3) Pressão/obrigação pessoal.
4) Contato com a área de pesquisa.
5) Auxílio financeiro.
6) Encontrar respostas para questionamentos 
próprios.

A frequência de citações encontradas para cada uma das subcategorias, bem como uma fase exemplificando cada uma delas podem ser vistas na Tabela 5 .

Tabela 5: Frequência de citações de cada subcategoria de motivações e citação retirada dos relatos referentes àquela subcategoria

\begin{tabular}{|c|c|c|}
\hline Subcategoria & Frequência de citações & Trecho exemplo da subcategoria \\
\hline 1 & 8 & "Então, procurei um professor da disciplina, área que sempre interessou muito também". \\
\hline 2 & 4 & $\begin{array}{l}\text { "(...) eu decidi que iria dar importância a essa atividade extracurricular, não porque já } \\
\text { me interessava por algum assunto em específico, mas porque eu queria poder acrescentar } \\
\text { essa atividade no meu currículo e me tornar um médico melhor". }\end{array}$ \\
\hline 3 & 4 & $\begin{array}{l}\text { "A este ponto, notei que muitas vezes buscamos a IC pela necessidade do que ouvimos } \\
\text { dos alunos dos anos superiores ao nosso, ficando mais como necessidade e menos } \\
\text { como envolvimento em áreas que gostaríamos de fato de pesquisar. Vejo esse problema } \\
\text { com outros colegas e noto que, de fato, a IC tornou-se mais uma obrigação imposta } \\
\text { aos alunos". }\end{array}$ \\
\hline 4 & 4 & $\begin{array}{l}\text { "(...) eu valorizava bastante a pesquisa e queria genuinamente contribuir para a ciência, } \\
\text { tanto que a bolsa de pesquisa era algo completamente secundário para mim". }\end{array}$ \\
\hline 5 & 1 & $\begin{array}{l}\text { "(...) e o que tinha me levado até lá fora um convite e a ideia de talvez conseguir ganhar } \\
\text { algum dinheiro durante a faculdade". }\end{array}$ \\
\hline 6 & 1 & $\begin{array}{l}\text { "Hoje sou orientado para responder duas perguntas que me surgiram a partir de } \\
\text { experiências próprias". }\end{array}$ \\
\hline
\end{tabular}

\section{DISCUSSÃO}

O estudo objetivou analisar as experiências que os alunos do $1^{\circ}$ ao $6^{\circ}$ ano de medicina da Unifesp tiveram com seus projetos de iniciação científica a partir de relatos escritos. Uma estimativa da participação dos estudantes nesse tipo de projeto pode ser feita a partir de dados oficiais da universidade, considerando que, em 2018, haviam 752 alunos ${ }^{10}$ matriculados no curso de medicina e que, nesse mesmo ano, uma pesquisa feita pela diretoria do curso como parte de um processo de creditação da universidade indicou que 310 alunos declararam estar ou que já haviam estado envolvidos em projetos científicos durante a graduação, voluntários ou com auxílio de instituição de fomento, indicando uma participação de cerca de $41 \%$, semelhante àquela encontrada na literatura ${ }^{7,11}$.

Os dados obtidos apontam que a maioria dos alunos participantes (60 dos 71 textos) relatam que suas experiências com os projetos de iniciação científica tiveram saldo positivo, estando alinhado com os dados apresentados na literatura ${ }^{7}$. Os 11 relatos categorizados como experiências negativas estavam homogeneamente distribuídos do primeiro ao sexto ano de graduação, não havendo indicativo de uma correlação entre a época do curso e uma experiência negativa no projeto de pesquisa.

Um ponto importante a ser discutido é a relação entre iniciação científica e o aprendizado do método científico. Método científico pode ser definido como "o conjunto das atividades sistemáticas e racionais que, com maior segurança e economia, permite alcançar o objetivo - conhecimentos válidos e verdadeiros -, traçando o caminho a ser seguido, detectando erros e auxiliando as decisões do cientista"12. Ele compreende múltiplas etapas a partir das quais, partindo da observação de fatos, surge um questionamento ou problema que permite a elaboração de hipóteses e a dedução de possíveis resultados. Essas hipóteses são testadas experimentalmente, sendo ou não aceitas a partir da comparação dos resultados obtidos e esperados. O contato com essa metodologia sistemática de raciocínio e a possibilidade, a partir dela, de analisar fatos de maneira crítica, é um dos principais benefícios citados na literatura advindos do contato com projetos científicos ainda na graduação ${ }^{1,3}$. Ao analisar os dados obtidos dos relatos, esse assunto é citado na subcategoria 1 dos "Pontos positivos" e 4 dos "Pontos negativos". No primeiro caso, essa é a subcategoria mais citada, demonstrando a importância que esse ponto teve nos relatos obtidos. Já quanto aos aspectos negativos, a falta de conhecimento prévio dessa metodologia aparece em quarto lugar.

A falta de conhecimento prévio sobre a metodologia científica, bem como a dificuldade de conciliar as obrigações da graduação com o projeto por falta de tempo (subcategoria 2 dos "Pontos negativos", estando em segundo lugar quanto ao número de citações) suscita a discussão sobre qual o atual papel do envolvimento dos alunos em projetos de iniciação científica tem nas faculdades de medicina brasileiras. As diretrizes curriculares nacionais para os cursos de medicina ${ }^{13}$, publicadas em 2014 pelo Ministério da Educação incluem, dentre as habilidades requisitadas ao egresso da faculdade de medicina, a aplicação de raciocínio científico na prática clínica, análise crítica de fontes, métodos e resultados 
bem como a identificação da necessidade de produção de novos conhecimentos científicos em saúde. Além disso, concursos para vagas de residência médica tem, dentre os quesitos analisados, publicação de artigos científicos, participação em congressos e envolvimento em projetos de iniciação científica ${ }^{14}$. Apesar disso, a falta de tempo para se dedicar a um projeto é um empecilho comumente citado na literatura ${ }^{7}$, bem como questões relativas à falta de incentivo institucional ${ }^{15}$ que, nessa pesquisa, não representou montante importante nos relatos analisados (subcategoria 5 de "Pontos Negativos"). Essa dicotomia entre a valorização da participação do aluno em projetos científicos e a falta de organização do curso médico para permitir tal envolvimento vem criando o debate sobre a necessidade do oferecimento de disciplinas, optativas ou obrigatórias, voltadas para tal temática, além de possíveis incentivos para a realização de um projeto científico durante o curso médico ou a obrigatoriedade de tal realização. No caso das disciplinas voltadas ao assunto, o maior exemplo brasileiro é a Universidade Federal Fluminense (UFF) que, desde 1996, oferece uma disciplina optativa do $2^{\circ}$ ao $8^{\circ}$ período da graduação, na qual os alunos são expostos a temática científica devendo, ao final do período, elaborar um trabalho de conclusão. Essa experiência já foi analisada na literatura no aspecto de influência em publicações de professores envolvidos e no perfil dos egressos que participaram do curso ${ }^{16}$. Na Unifesp, após a reforma do currículo médico ocorrida em 2018, foi introduzida uma disciplina nos dois primeiros anos do curso chamada "Iniciação à Pesquisa Científica", na qual os alunos são apresentados à metodologia científica, aos tipos de estudo existentes, a ética em pesquisa, além de serem capacitados, por meio do contato com bases de dados e ferramentas de busca, a realizarem pesquisa em literatura científica. Ao final da disciplina, os graduandos devem apresentar um projeto de pesquisa desenvolvido ao longo do período. Especificamente sobre a temática da iniciação científica, o conteúdo programático da disciplina cita como um dos objetivos "oferecer ferramentas teóricas e práticas para uma iniciação científica qualificada"17. Devido à recente introdução curricular, os impactos da iniciativa ainda não foram analisados.

No que tange o incentivo para a realização de projetos de iniciação científica, a discussão é mais presente em universidades estrangeiras. Universidades norte-americanas (por exemplo, a Universidade de Stanford, a Universidade de Harvard e a Universidade da Pennsylvania) comumente apoiam, de maneira formal, alunos que queiram utilizar um ano de sua graduação para realizar pesquisa médica ${ }^{18}$. Esses incentivos são motivados por uma diminuição dos médicos interessados na carreira científica, argumentando que a construção de uma carreira acadêmica deve ser iniciada ainda na graduação ${ }^{19} \mathrm{e}$, além disso, nos possíveis benefícios que esse envolvimento poderia trazer para o estudante, como estímulo a educação constante, leitura crítica de literatura médica e melhora do currículo ${ }^{20}$. Outro exemplo é o programa norueguês, iniciado em 2006, visando aumentar a atração de estudantes de medicina para a área acadêmica, no qual é oferecido apoio financeiro ao graduando que queira dedicar dois anos, sendo um adicional aos seis da graduação, à realização de pesquisa científica ${ }^{5}$. No Brasil, esse tipo de incentivo se dá, principalmente, pela distribuição de bolsas por agências de fomento, sendo que esse aspecto foi encontrado como ponto positivo (subcategoria 7) e motivação (subcategoria 5), além da falta desse incentivo ser citada como ponto negativo (subcategoria 10) nos relatos analisados. Algo semelhante ao que acontece em universidades americanas é o programa de MD-Ph.D. existente em algumas faculdades médicas brasileiras, no qual o aluno de medicina pode ingressar num programa de pós-graduação antes do término da graduação e, com 2 ou 3 anos adicionais ao currículo normal, obter o título de $\mathrm{PhD}^{21}$.

Porém, além da implementação de incentivos, é necessário garantir a qualidade desses programas e a capacitação técnica e intelectual dos alunos participantes. Possíveis malefícios da obrigatoriedade de realização de uma pesquisa científica durante a graduação médica seriam forçar alunos que não estão interessados no tema a se envolverem, necessidade de retirada de outros conteúdos curriculares, falta de tempo para se dedicar a outros aspectos de interesse, necessidade de maiores gastos por parte das instituições de ensino para a implementação dos programas de pesquisa ${ }^{20}$.

O segundo "Ponto positivo" mais citado (subcategoria 2) foi a possibilidade de desenvolver habilidades pessoais, como organização de tempo, trabalho em equipe e proatividade. Trabalhos com estudantes de cursos que não a medicina apontam para benefícios como tolerância para obstáculos, independência e autoconfiança $^{22}$. Outra habilidade citada na literatura é a comunicação ${ }^{7,19}$, desenvolvida pela necessidade de organizar de forma clara os dados obtidos em relatórios e artigos, bem como na possibilidade de apresentar esses dados em congressos. Esse achado é interessante pois mostra possibilidade de ganho de habilidades que não estão diretamente relacionadas ao projeto científico em si, mas sim em sua gestão e execução, e que também podem ter aplicações futuras na vida profissional desses estudantes.

Uma questão negativa nessa discussão é a pressão criada, principalmente pela concorrência dos concursos para residência médica, para que o graduando se envolva em algum projeto de iniciação científica. Nos relatos analisados, essa motivação foi citada (subcategoria 3 das "Motivações") e isso também é presente na literatura sobre o tema. Em uma análise dos motivos pelos quais alunos em universidades americanas optaram por reservar um ano de suas graduações para se envolverem em pesquisas, a principal motivação foi a competitividade da residência médica ${ }^{18}$, sendo que um terço dos alunos que escolheram tal 
opção não o fariam se a residência médica não valorizasse esse aspecto. No Brasil, pesquisas sobre o envolvimento dos graduandos de medicina em atividades extracurriculares, dentre elas projetos de iniciação científica, indicam, dentre as principais motivações, o enriquecimento do currículo ${ }^{7,11}$. Obviamente, a preocupação do aluno com seu currículo e com o processo seletivo da residência médica não é, por si, um problema. Porém, isso gera uma pressão nos estudantes a medida que veem outros colegas se envolverem em projetos científicos, o que pode gerar alunos desmotivados com seus projetos ${ }^{18}$. Um possível reflexo dessa situação é uma produção científica de baixa qualidade, uma vez que o aluno não é envolvido de fato no projeto. Uma pesquisa que avaliou a produção científica feita por estudantes de medicina ao longo dos anos demonstrou que, apesar de um aumento importante no número de publicações, essas quase não são citadas ${ }^{23}$, mostrando um déficit de qualidade nessas pesquisas.

Um assunto recorrente nos relatos analisados foi a importância da relação entre estudante e orientador durante a elaboração e execução do projeto científico, estando uma boa relação em terceiro lugar entre os "Pontos positivos" (subcategoria 3) e uma relação ruim em primeiro lugar (subcategoria 1) entre os "Pontos negativos". Na literatura, uma pesquisa feita com graduandos de medicina da Unesp indicou que os principais fatores que eles levaram em consideração ao escolher seus orientadores foram tempo disponível, motivação para comandar a pesquisa e didática demonstrada em sala de aula. Todos os alunos participantes citaram que um relacionamento conflituoso com um orientador seria um ponto negativo. $\mathrm{O}$ mesmo trabalho cita como fatores relacionados ao sucesso do orientador, do ponto de vista do orientando, seu conhecimento, capacidade de se expressar de forma clara e a maneira com que este lida com situações de conflito 7 . O orientador tem o papel de auxiliar o aluno de iniciação científica que, devido à falta de experiência, não possui as habilidades necessárias para a condução autônoma de um projeto de pesquisa. No entanto, existem muitas situações nas quais os alunos não são adequadamente amparados nesse processo e, além disso, situações nas quais há uma relação conflituosa entre aluno e orientador ${ }^{24}$. Isso é danoso em vários aspectos: primeiramente, há risco de que os supostos benefícios advindos da participação em projetos de pesquisa não sejam plenamente desenvolvidos por essa lacuna de orientação. Essa situação pode também afetar o empenho e envolvimento do aluno na pesquisa, seja porque ele não tem claras orientações de como desenvolver o projeto, seja porque o ambiente criado é desmotivador para ele, o que acaba afetando o resultado final da pesquisa.

Por fim, a literatura discute a importância da pesquisa na graduação como estímulo para escolha de uma futura carreira acadêmica. Como já definido ${ }^{1}$, a iniciação científica é o primeiro contato com o mundo acadêmico de um estudante universitário, sendo essencial para que ele possa refletir e amadurecer seu interesse pela área, podendo inclusive fazer dela sua carreira profissional. Isso se pauta na ideia de que uma carreira em ciência seria construída em níveis e que a possibilidade de participar de uma pesquisa ainda como estudante seria o primeiro deles ${ }^{19}$. Em nossa pesquisa, esse não foi um ganho bastante citado $\left(6^{\circ}\right.$ lugar na categoria "Pontos positivos"). Pesquisas prévias citam índices de interesse de $28 \%{ }^{7}$ e até $60 \%$ dos alunos envolvidos em pesquisa ${ }^{25}$ em seguir carreira acadêmica. Como já supracitado, outros países como os Estados Unidos e a Noruega desenvolveram programas nacionais de incentivo à pesquisa na graduação médica justamente devido a um desinteresse por parte dos estudantes em seguir carreira acadêmica ${ }^{5,18}$. No Brasil, inexiste um programa oficial de incentivo a esse tipo de carreira focado nos estudantes de medicina.

\section{CONCLUSÕES}

Nossa pesquisa evidenciou que a maioria dos estudantes de medicina da UNIFESP relatou uma boa experiência com seus projetos de iniciação científica, citando como principais pontos positivos o contato e aprendizado do método científico e o desenvolvimento pessoal e como principais pontos negativos uma relação conflituosa com o orientador e a falta de tempo. Com isso, é possível ter um panorama de como essa atividade extracurricular é vista pelos estudantes de medicina em nossa universidade, além de entender seus pontos fortes e fragilidades.

Como pontos deficitários do trabalho, podemos citar a falta de discriminação na análise entre áreas das pesquisas feitas pelos estudantes ou entre os anos de graduação em que os alunos estavam quando relataram suas experiências. Outra questão, que é inerente ao método utilizado, é a subjetividade na categorização e subcategorização dos relatos e dos pontos positivos e negativos neles citados.

$\mathrm{O}$ uso do relato escrito e anônimo permitiu uma adequada expressão por parte dos estudantes de suas experiências com projetos científicos, mostrando ser uma metodologia adequada. Essa metodologia poderia ser também aplicada em análises futuras, como entrevistas com orientadores ou no estudo pormenorizado de cada um dos pontos positivos e negativos encontrados na pesquisa.

Faz-se necessário então discutir maneiras de incorporar a pesquisa na grade curricular oficial das faculdades de medicina brasileiras, bem como maior suporte institucional para a execução de tais projetos, permitindo que as suas potencialidades sejam desenvolvidas. 
Agradecimentos: Agradecemos ao Conselho Nacional de Desenvolvimento Científico e Tecnológico (CNPq) pela bolsa do Programa Institucional de Bolsas de Iniciação Científica (PIBIC).

Agência de fomento: $\mathrm{CNPq}$ - Conselho Nacional de Pesquisa.

Colaboração dos autores: Lucas Henrique Pereira: desenvolvimento do projeto, análise das narrativas, pesquisa bibliográfica, escrita do artigo. Mariana Cabral Schveitzer: orientação e desenvolvimento do projeto, revisão das análises, revisão do artigo.

\section{REFERÊNCIAS}

1. Silva LF. Iniciação científica - contexto e aspectos práticos. Rev Med (São Paulo). 2012;91(2):128-36. doi: https://doi. org/10.11606/issn.1679-9836.v91i2p128-136.

2. Massi L, Queiroz SL. Estudos sobre iniciação científica no Brasil: uma revisão. Cad Pes ;2010;40(139):173-97. doi: https://doi.org/10.1590/S0100-15742010000100009.

3. Fava-de-Moraes F, Fava M. A iniciação científica: muitas vantagens e poucos riscos. São Paulo Perspec. 2000;14(1):73-7. doi: https://doi.org/10.1590/S010288392000000100008

4. Tenorio MP, Beraldi G. Iniciação científica no Brasil e nos cursos de medicina. Rev Assoc Med Bras. 2010;56(4):3903. doi: 10.1590/S0104-42302010000400007.

5. Hunskaar S, Breivik J, Siebke M, Tømmeras K, Figenschau K, Hansen JB. Evaluation of the medical student research programme in Norwegian medical schools. A survey of students and supervisors. BMC Med Educ. 2009;9:43. doi: https://doi.org/10.1186/1472-6920-9-43.

6. Oliveira NA, Alves LA, Luz MR. Iniciação científica na graduação: o que diz o estudante de medicina? Rev Bras Educ Med. 2008;32(3):309-14. doi: https://doi.org/10.1590/ S0100-55022008000300005.

7. Oliveira CC, Souza RC, Abe EHS, Moz LES, Carvalho LR, Domingues MA. Undergraduate research in medical education: a descriptive study of student's views. BMC Med Educ. 2014;14:51. doi: https://doi.org/10.1186/14726920-14-51.

8. Hoga LAK, Borges ALV. Pesquisa empírica em saúde: guia prático para iniciantes [citado em 24 mar 2020]. 2016. Disponível em: http://www.ee.usp.br/cartilhas/ pesquisa_empirica_saude_2016.pdf.

9. Palinkas LA, Horwitz SM, Green CA, Wisdom JP, Duan N, Hoagwood K. Purposeful sampling for qualitative data collection and analysis in mixed method implementation research. Adm Policy Ment Health. 2015;42(5):533-44. doi: https://doi.org/10.1007/s10488-013-0528-y.

10. Universidade Federal de São Paulo. Números e indicadores. São Paulo: Unifesp; 2015 [citado em 24 mar 2020 ]. Disponível em: https://www.unifesp.br/reitoria/indicadores/ unifesp-em-numeros.

11. Vieira E, Barbieri C, Vilela D, Ianhez Junior E, Tome $\mathrm{F}$, Woida $\mathrm{F}$, et al. O que eles fazem depois da aula? As atividades extracurriculares dos alunos de ciências médicas da FMRP-USP. Medicina (Ribeirão Preto). 2004;37(1/2). doi: https://doi.org/10.11606/issn.2176-7262. v37i1/2p84-90.

12. Marconi MA, Lakatos EM. Fundamentos da metodologia científica. São Paulo: Editora Atlas; 2003.

13. Brasil. Ministério da Educação. Resolução CNE/CES 1/2014. Institui Diretrizes Curriculares Nacionais do Curso de Graduação em Medicina e dá outras providências. Diário
Oficial da União, Brasília, 23 jun. 2014. Seção 1, p. 8-11.

14. Chaves HL, Borges LB, Guimarães DC, Cavalcanti LPG. Vagas para residência médica no Brasil: onde estão e o que é avaliado. Rev Bras Educ Med. 2013;37(4):557-65. doi: https://doi.org/10.1590/S0100-55022013000400011.

15. Oliveira NA, Luz MR, Saraiva RM, Alves LA. Students views of research training programmes in medical schools. Med Educ. 2011;45(7):748-55. doi: https://doi.org/10.1111/ j.1365-2923.2011.03986.x.

16. Cyrillo RJT, Setubal S, Junior Cyro TS, Velarde LGC, Mattos ANMT, Cardoso RBB, et al. Influência de um programa de iniciação científica de graduação no perfil profissional dos médicos recém-formados. Rev Port Pneumol. 2010;16(5). doi: https://doi.org/10.1016/S08732159(15)30072-6.

17. Universidade Federal de São Paulo. Conteúdo Programático das UC's. São Paulo: Unifesp; 2018 [citado em 24 mar 2020]. Disponível em: https://www.unifesp.br/reitoria/prograd/ pro-reitoria-de-graduacao/cursos/conteudoprogramaticodas-uc-s.

18. Pathipati AS, Taleghani N. Research in medical school: a survey evaluating why medical students take research years. Cureus.2016;8(8):e741. doi: https://doi.org/10.7759/ cureus. 741 .

19. Gonzalez C. Undergraduate research, graduate mentoring and the University's Mission. Science. 2001;293(5535):1624-6. doi: https://doi.org/10.1126/science.1062714.

20. Parsonnet J, Gruppuso PA, Kanter SL, Boninger M. Requires vs. Elective Research and in Depth Scholarship Programs in the Medical Student Curriculum. Acad Med. 2010;85(3):405-8. doi: https://doi.org/10.1097/ ACM.0b013e3181ccede 4 .

21. Oliveira RV. O programa de formação em pesquisa médica MD-PhD da UFRJ [tese]. Rio de Janeiro: Universidade Federal do Rio de Janeiro; 2009. Disponível em: http:// www.dominiopublico.gov.br/pesquisa/DetalheObraForm. do? select_action $=\&$ co_obra $=169746$.

22. Petrella JK, Jung AP. Undergraduate research: importance, benefits, and challenges. Int J Exerc Sci. 2008;1(3):91-5.

23. Wickramasinghe DP, Perera CS, Senarathna S, Samarasekera DN. Patterns and trends of medical student research. BMC Med Educ. 2013;13:175. doi: https://doi.org/10.1186/14726920-13-175.

24. Palacios M. Pesquisa científica como eixo integrador da formação e prática médica. Rev Bras Educ Med. 2011;35(4):443-4. doi: https://doi.org/10.1590/S010055022011000400001 .

25. Jacobs CD, Cross PC. The value of medical student research: the experience at Stanford University School of Medicine. Med Educ. 1995;29(5):342-6. doi: https://doi. org/10.1111/j.1365-2923.1995.tb00023.x.

Submetido: 23.03 .2020

Aceito: 21.07.2020 